\title{
Studying the efficiency of a complex individual protective device
}

\author{
Serhii Cheberiachko ${ }^{1 *}$, Olena Yavorska ${ }^{1}$,Volodymyr Hridiaiev ${ }^{2}$, and Andrii Yavorskyi $^{3}$ \\ ${ }^{1}$ Dnipro University of Technology, Department of Labour Protection and Civil Safety, \\ 19 Yavornytskoho Ave., 49005 Dnipro, Ukraine \\ ${ }^{2}$ PJSC “Avdiivka Coke Plant", 1 Industrial St, 86066 Avdiivka, Ukraine \\ ${ }^{3}$ Dnipro University of Technology, Department of Underground Mining, 19 Yavornytskoho Ave., \\ 49005 Dnipro, Ukraine
}

\begin{abstract}
Objective is to study efficiency of a complex protective device including coefficients of penetration and suction of aerosols for dust halfmasks of various designs. The half-masks were tested experimentally on specially designed laboratory stands with the help of volunteer-testees; the tests included specifications according to EN 149, EN 352-1, ISO 6942. The studies have demonstrated that a complex protective device for workers is rather efficient providing average coefficient of suction being $1.5 \%$ that is almost by $30 \%$ less than the values of standard filtering respirators of similar protection class. Noise attenuation within the range of $4000-8000 \mathrm{~Hz}$ is from 19 to $26.7 \mathrm{~dB}$; within the range of speech frequency $(0.5 \div 2.0 \mathrm{kHz})$, acoustic efficiency is up to $8 \div 16 \mathrm{~dB}$ helping preserve the possibility of communication and timely reaction to warning signals. Use of thermal protecting elements makes it possible to reduce temperature of head heating by $80 \%$ comparing to the results obtained without the protective device application. The developed balaclava with the built-in dust respirator and hearing protection devices may be used in the context of the corresponding filter class up to $12 \mathrm{MAC}$ in terms of the most hazardous aerosols, when noise level is up to $14 \mathrm{~dB}$ within $2000-$ $8000 \mathrm{~Hz}$ frequency range; moreover, it provides slow temperature rise up to $2{ }^{\circ} \mathrm{C}$ per minute.
\end{abstract}

\section{Introduction}

By-product coking industry is the important link of metallurgical complex of Ukraine; the industry enterprises apply coking method to process chemically bituminous coal (BC) with the obtaining of metallurgical coke, coking gas, coking by-products (ammonia sulfate, sulfur, sulfurated hydrogen etc.) as well as a range of organic compounds being valuable raw material for chemical industry.

It is known that insufficient working conditions at the enterprises of mining, coal, and coke-chemical industries are stipulated first of all by air contamination with toxic aerodisperse particles of various origin (dust, smoke, fog), gas- and steam-like compounds, and high level of industrial noise within the working zones [1-5]. All the factors have

\footnotetext{
* Corresponding author: sicheb@ukr.net
} 
following negative effects: chronicle fatigue, irritability, headache, impaired concentration and decreased reaction rate with further injures of breathing organs, early hearing loss as well as abnormal activity of central and vegetative nervous and cardiovascular systems. It is obvious that under conditions when engineering and technical measures do not demonstrate proper results, the only way to prevent occupational diseases is the application of modern complex individual protective devices (CIPD), which include: respiratory protection devices (RPD) and hearing protection devices (HPD). Nowadays, the development of those devices is of high importance.

\section{Analysis of the available publications}

Nowadays, complex means to protect hearing, head, and respiratory organs are gaining popularity. They are made in the form of balaclavas. Taking into consideration the fact that due to certain reasons and factors mentioned earlier, the results of laboratory tests do not comply with the values of efficiency obtained under working conditions in terms of inserts, earpieces, and dust respirators, and the fact that constant wearing of the devices prevents from communicating, reacting to signals and commands and even may be incompatible with the requirements for safe working, manufacturing of complex devices in form of balaclava to protect against noise and dust is rather expedient [6]. Their use may change the situation completely as their expected advantage is in the fact that there is no difference between indices determined by laboratory and field testing.

It is clear that IPD should provide comfortable conditions during their application and maximum protection in terms of various hazardous factors. That may be obtained by the use of various specific materials (e.g. WINDSTOPPER to protect against wind, Polartec against high temperatures, Arsenal and Kevlar - against fire and sparkles, Carbon $X-$ against toxic gases), development of corresponding instructions, and use of up-to-date technological solutions to produce the required facilities $[7,8]$.

Information search has helped to determine that there is a great variety of complex protective devices. Their structure is based on a balaclava protecting human head, face, neck, shoulders and, sometimes, upper part of chest; in addition, it is often equipped with the embedded specialized devices to protect respiratory organs, hearing organs, and head. For instance, balaclava ColdAvenger Balaclava Pro protects against microorganisms available in the air owing to soft biocompatible polyurethane used to manufacture a dismountable mask; the material absorbs moisture from the facial surface and breathing zone. Balaclavas Windbloc Thor V2 BASK and Ergodyne N-Ferno 6970 Extreme Balaclava have similar structure. Their anatomic design guarantees protection of head, neck and part of face against the effect of low temperatures. In case of strong wind, face is covered with special dismountable mask with breathing holes [9].

Testing the efficiency of individual protecting devices is the important stage of its development; the device efficiency is proved by the testing the protecting properties stated by a manufacturer under laboratory conditions and checking if they are in compliance with certain standards, i.e. DSTU EN 149:2003, DSTU EN 352-1:2002, DSTU EN 352-7:2005, and DSTU ISO 6942-2001. Those normative acts envisage a set of procedures aimed at determining protective and ergonomic properties of noise- and heat-aerosol individual protective devices. Defining the efficiency of reduction of the hazardous factor effect is the essential element of the efficiency evaluation since that is the index to take into account while selecting individual protective devices for specific operating conditions. The mentioned index is calculated in terms of laboratory tests with the help of volunteers [2].

To evaluate respirators, it is required to determine penetration coefficient of the contaminated air depending both upon the filter and insulating properties of the half-mask obturator. Taking into consideration the fact that aerosol penetration immediately through 
high-efficiency filters is insignificant, i.e. slipping of particles through a filter is minimal, there is the necessity to determine interrelation between the properties of half-masks responsible for respirators quality and coefficient of their protection. To do that, various methods described in papers $[3,4]$ are used.

Efficiency of hearing protection devices is determined according to SNR (Single Number Rating or Sounds Noise Reduction) characteristics, i.e. averaged index of decrease in noise level in terms of low, medium, and high frequencies used in European countries to determine efficiency of noise-drowning devices. That is the dimensionless value equal to the ratio of useful signal strength (significant information) to the background noise strength (unwanted signal).

Protective properties of special-purpose clothing to protect against high or low temperatures are determined according to its thermal resistance and specific air-penetrating metrological conditions.

\section{Statement of the problem}

When workers perform their duties under harmful conditions, they are required to use several individual protection devices simultaneously. That results in certain inconveniences related to combination of protective devices, their proper selection, and unhandiness. In particular, helmet liner made in the form of balaclava, is practically incompatible with RPD. When earpieces are used, it is required to put the liner on and off because if earpieces are placed upon the balaclava, then protective parameters of HPD worsen. Moreover, topical problem is to provide the communication without putting the HPD off and to make it possible to hear warning signals. Thus, there is the necessity in reliable fixation on a face (so that the mask does not slip and form additional gaps along the obturation line resulting in considerable deterioration of insulating properties) [10].

For the first time, specialists of Physical and Chemical Institute of Environmental Protection and Human of the Ministry of Education and Sciences of Ukraine and NAS of Ukraine have developed a complex individual protection device of fast adjustment (CIPD); the device has combined balaclava 1 equipped with the corresponding filtering half-masks 4, noise-attenuating elements 2 and thermal accumulating elements 3 (Fig. 1). All the components are connected with the help of the shank end of a valve unit which is built into the related mounting openings of the balaclava and half-mask and fixed with the help of a nut.
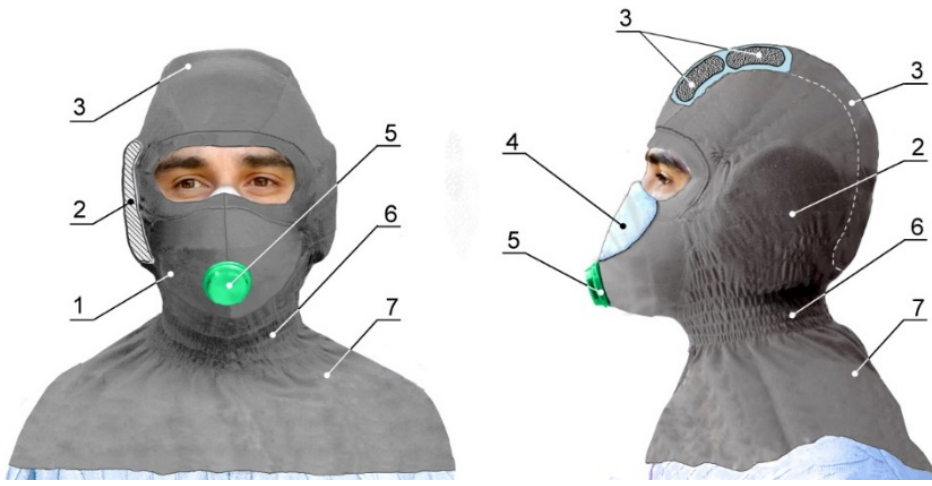

Fig. 1. CIPD of fast adjustment: 1-balaclava; 2-noise-attenuating elements; 3 -thermal accumulating elements; 4 - filtering gas and dust half-masks; 5 - valve unit; 6 - collar; 7 - cape [11].

Owing to the structure, being modeled taking into account anatomic features of human head and neck, and use of elastic thermal-resistant fabric Indura, balaclava 1 performs its 
functions and provides fast adjustment and proper contact of the half-mask, fixation of noise-attenuating elements 2 within the ear rims and their comfortable carrying during all the period of CIPD use. Collar 6 and cape 7 are aimed at preventing aerodisperse particles from entering the under-mask area and to the face as well as protecting neck and shoulder girdle against mechanical and thermal injuries.

In terms of CIPD, breathing organs are protected by a half-mask of well-known respirator Snizhok - RPD which has proved itself to be good while operating under different conditions [12]. The half-mask (Fig. 2) consists of a shape-forming frame 1 along the external and external surface of which particle filter 3 with changeable geometry of obturation line and/or gas filter 4 are set. Valve unit 5 (Fig. 1) helps decrease breathing resistance, eliminate heat and moisture from the under-mask area, and provide normalized content of carbon dioxide.

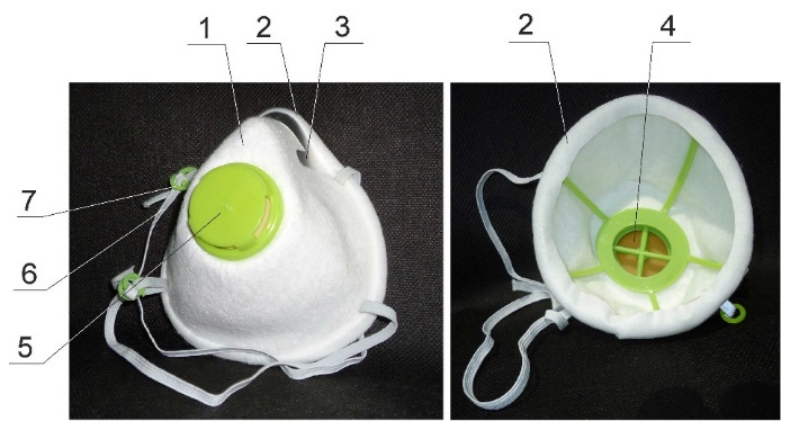

Fig. 2. Filtering half-mask from aerosols: 1 - Filtering half body; 2 -obturator with elastic cord; 3 - metal pressure plate; 4 - clamp with exhalation valve leaf ; 5 - face; 6 - headset; 7 -rings.

Noise-attenuating elements (NAE) were designed taking into consideration specificity of working conditions and level of industrial noise at mining and metallurgical enterprises: the elements are arranged in "special pockets" 2 (Fig. 1) located on the internal balaclava side within the zone of ear rims. The elements consist of two layers of homogeneous noiseattenuating material; they are based on synthetic caoutchoucs, being laminated unilaterally with fabric sheet, and metal plate located between their layers; external NAE part is covered with knitted fabric.

CIPD is additionally equipped with thermal accumulating elements 3 (TAE) (Fig. 2) to reduce external thermal load upon a user. TAEs, located within the occipitofrontal part of balaclava, are applied to have more comfortable conditions for a thermal regulation system during certain period of time [13] and to maintain thermal homeostasis in terms of increased temperatures owing to the use of the substance with phase transitions accompanied by heat absorption, e.g. paraffins, waxes, and their mixtures with organic substances. However, in case of contact with head skin covers and according to the safety requirements at fire-hazardous enterprises, they should be nontoxical, inflammable, and incombustible having low temperature of phase transformations $\left(>34^{\circ} \mathrm{C}\right)$. Sodium sulfate decahydrate applied in the TAE is completely compatible with the requirements; distribution of crystals within TAE packing volume is uniform owing to the addition of inert fillers (sintepon, polymer mass fiber etc.) in 1:1 ratio.

It should be pointed out that the development of such specialized devices as balaclava has involved the fact that the material should not cause considerable breathing resistance; in terms of two-layer structure, external layer is made of hydrophobic, air-penetrating materials while internal layer is made of hypoallergenic moisture- and air-penetrating materials. There is the possibility to use it along with the protective helmet as well as with breathing and visual individual protective devices. In terms of possible operation under 
conditions of increased noise, the balaclava was equipped with dismountable antinoise pads.

Objective of the research is to study the efficiency of complex dust and noise individual protective devices for workers.

\section{Methods of the research}

CIPD protective properties were tested involving sodium chloride test-aerosol. Fig. 3 represents the plant scheme.

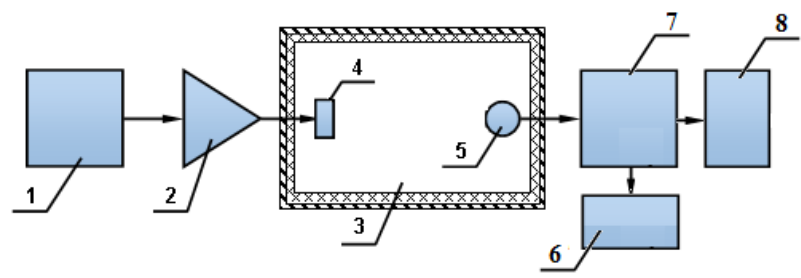

Fig. 3. Block scheme of the plant to test the properties of protective efficiency of an individual protective device: 1 -aerosol generator; 2 -mixer; 3 -testing chamber; 4 -aerosol diffusor; 5 dummy-head; 6 - aspirator; 7 - spectrophotometer; 8 - computer.

Essence of the method is as follows: special sodium chloride mixture in generator 1 (Collison dispenser for sodium chloride with $8-10 \mathrm{mg} / \mathrm{m}^{3}$ concentration) was supplied with a specified rate $(100 \mathrm{l} / \mathrm{min})$ into testing chamber 3 through mixer 2 and aerosol dispenser 4 where the required concentration of the testing mixture was provided. Protective device is mounted on dummy-head 5, in chamber 3. Aspirator 6 was used to take air with the rate of $95 \mathrm{l} / \mathrm{min}$ from the under-mask area of a dummy; further, the air was sent to spectrophotometer Selmi C-115E (7) to determine its concentration and penetration coefficient of a half-mask. As a result of device 8 operation, special software was used to calculated coefficient of protection and suction as a ratio of test-aerosol concentrations before and after CIPD application $[14,16]$.

Acoustic efficiency of noise-attenuating elements was determined with the help of the device (Fig. 4) by audiometry within pure sound range from $63-8000 \mathrm{~Hz}$ with one-octave step according to averaged difference of sound pressure both for NAE-protected and NAEunprotected sound receiver. The receiver was mounted into the dummy-head at the level of its ear canal, and the dummy was placed into the echo-free chamber. Such a solution has made it possible not only to fix accurately the position of sound receiver in terms of all the experiments, buts also to model, in certain approximation, sound propagation along peripheral canals which effect is stipulated by the difference between physical and audiometric efficiency of noise-attenuating materials by $10-15 \mathrm{~dB}$ [15].

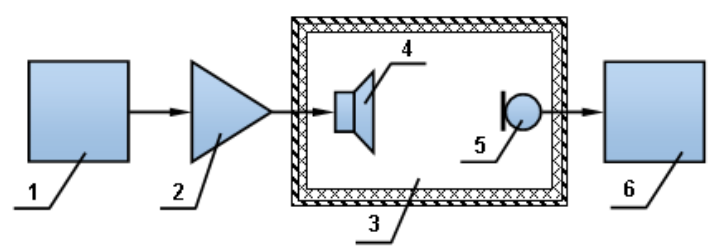

Fig. 4. Block scheme of a plant to test acoustic efficiency of HPD: 1 - signal generator; 2 - power amplifier; 3 - echo-free chamber; 4 and 5 - generator and receiver of sound signals respectively; 6 computer. 
The fixed pure sound tones of constant amplitude were represented by means of software signal generator 1; power amplifier 2, and broadband generator 4 (Fig. 4). Software package WaveTool (Free) was used to measure and process amplitude, frequency, and format of signals coming from sound receiver 5.

Fig. 5 demonstrates a block-scheme of the plant to study dynamics of temperature under balaclava equipped with TAE under the effect of high external temperature.

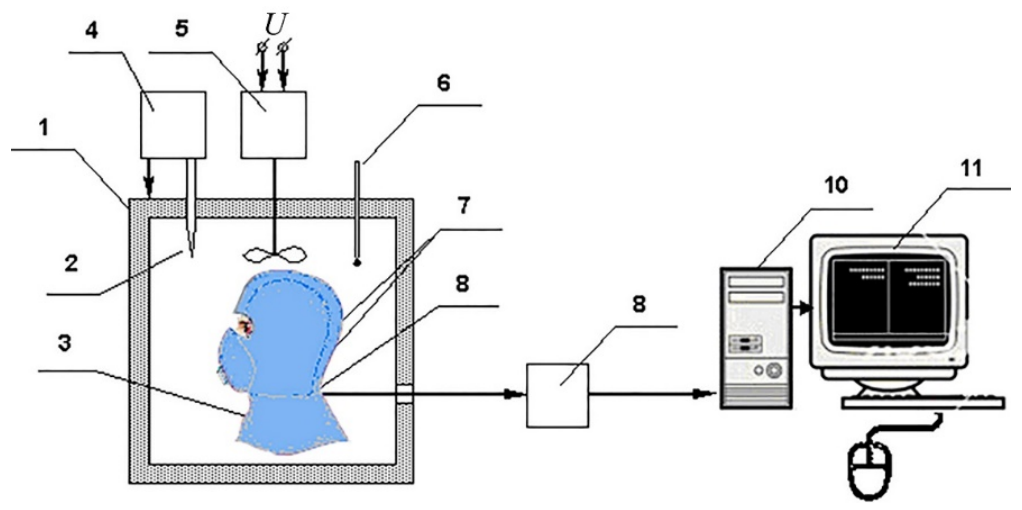

Fig. 5. Block scheme of a plant to determine dynamics in temperature changes under balaclava: 1 SUP-4c camera with adjustable temperature mode; 2 - adjustable thermal couple; 3 - balaclava; 4 temperature controller Щ4538; 5 - fan; 6 - control thermometer; 7 -digital heat sensors DS18S20 (shown conventionally); 8 - junction box; 9 - converter of heat sensor signals DS9097; 10 - system unit; 11 - display.

To provide minimum heat transfer, a dummy-head, with calibrated digital heat sensors DS18S20 mounted on its frontal, parietal, and occipital parts under TAE [17], was made of polyurethane foam; control heat censor fixing air temperature in the chamber was placed on external part of balaclava beyond the zone of TAE location. Measuring results were recorded into log-file in real-time mode and processed by means of MS Excel program.

Tests were carried out with the help of five volunteers who wore the protective device equipped with noise-attenuating and thermal-compensating elements as follows. Balaclava is put on a head so that the observation hole coincides with the eye zone, noise-attenuating elements close the ear rims, and thermal-compensating elements were within the occipitofrontal zone. In such a way, acoustic pressure and thermal effect decrease. If incompliance of the worn half-mask with the standards was observed in the process of testing, the process was brought to stop and resumed after elimination of the drawback.

Standard exercises indicated in EN 149 were done while determining coefficient of protection. Efficiency of a similar-type standard filtering half-mask inserted into the balaclava was evaluated additionally to compare parameters of different protective devices.

\section{Results of the research and discussion}

Significantly lower values of coefficients of suction of sodium chloride test-aerosol in CIPD than in other respirators selected randomly prove perfect parameters of the aforementioned engineering solution as for breathing organs protections. According to (Fig. 6), average values of CIPD coefficient of suction is $1.5 \%$ being almost $30 \%$ less than the indices of filtering respirators of similar protection class. 


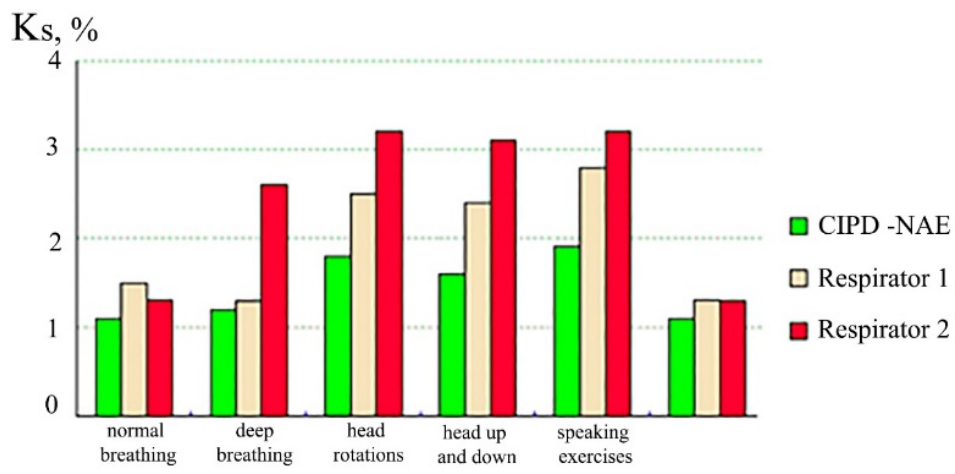

Fig. 6. Results of determining coefficient of suction when a testee is performing different exercises.

In our opinion, that is connected with the fact that elastic material of the balaclava favours more uniform and leak-proof contact with a face along the obturation line; moreover, the material acts as the additional fort-filter with changeable penetration coefficient favouring prolonged effect of aerosol filters. The latter conclusion is confirmed by the increased coefficient of aerosol catching in terms of the most penetrating particles of $0.2-0.4 \mathrm{mcm}$ (Fig. 7). According to the obtained data, the protective device may be included into the second class of protection; it may be used when boundary admissible concentrations are 12 times higher.

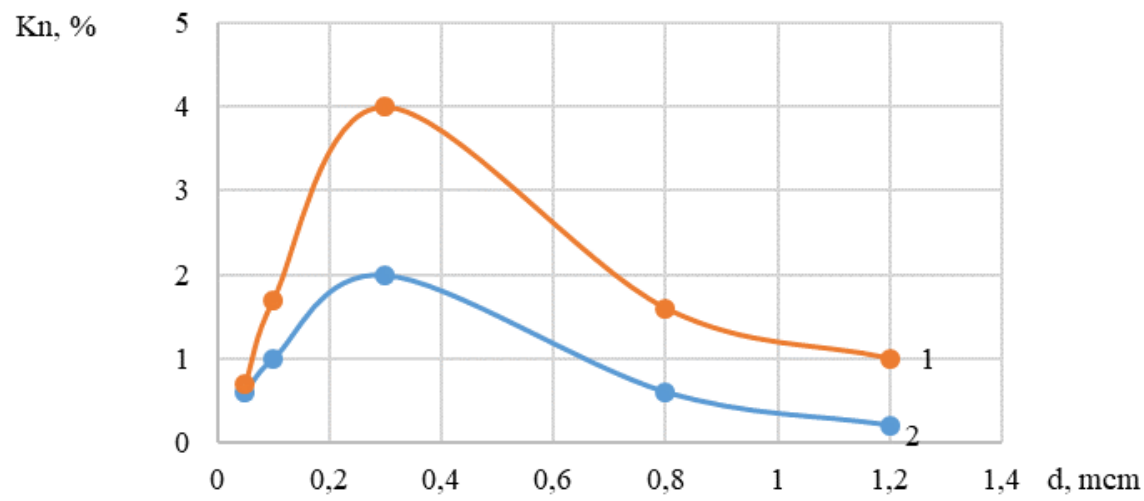

Fig. 7. Dependence of penetration coefficient of sodium chloride test-aerosol: 1 - standard halfmask; 2 - complex protective device (CIPD).

Data on studies of acoustic efficiency of the developed NAE, represented in Fig. 8 and Table 1 show that:

- noise attenuation within $4000-8000 \mathrm{~Hz}$ frequency, which is considered to be the most hazardous one for hearing organs [17], is from 19 to $26.7 \mathrm{~dB}$;

- in terms of voice frequency $(0.5 \div 2.0 \mathrm{kHz})$, acoustic efficiency reaches up to $8 \div 16 \mathrm{~dB}$, thus the ability to communicate and react timely to warning signals is preserved;

- balaclava material demonstrates practically no noise-attenuating ability within the mentioned frequency range: spread of values in all the experiments is within the limits of statistic error being not more than $\pm 2 \mathrm{Db}$. 


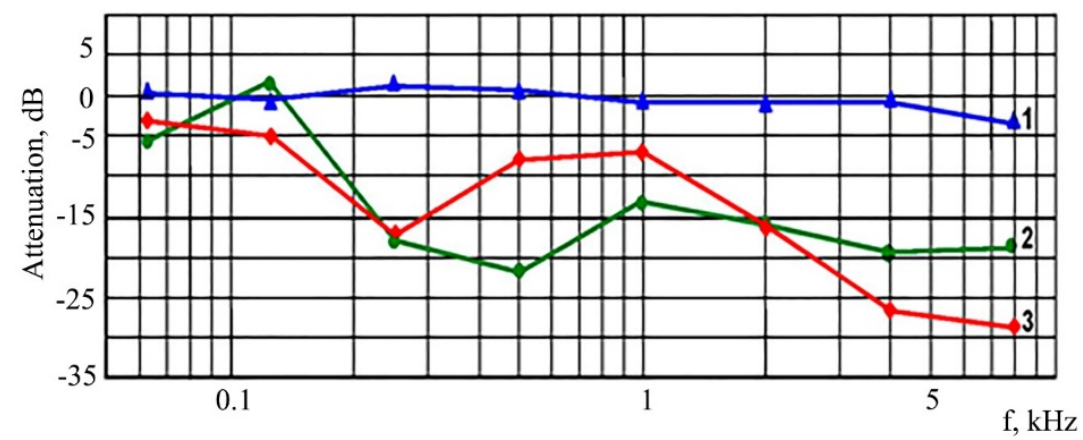

Fig. 8. Results of laboratory tests of NAE: 1-balaclava; 2-headphones ED1H Ear Defender (Sweden); 3 - test sample of NAE.

Table 1. Generalized data on measurements of acoustic efficiency of NAE samples from the test batch.

\begin{tabular}{|l|c|c|c|c|c|c|c|c|}
\hline \multirow{2}{*}{ Control parameter } & \multicolumn{7}{|c|}{ Frequency, Hz } \\
\cline { 2 - 9 } & 63 & 125 & 250 & 500 & 1000 & 2000 & 4000 & 8000 \\
\hline $\begin{array}{l}\text { Acoustic efficiency, } \\
\mathrm{dB}\end{array}$ & $1.5 \pm 0.3$ & $5.4 \pm 0.3$ & $12.7 \pm 1.9$ & $8.0 \pm 1.7$ & $2.2 \pm 0.2$ & $16.0 \pm 1.9$ & $19.8 \pm 1.1$ & $26.7 \pm 0.5$ \\
\hline
\end{tabular}

Comparison of acoustic efficiency of noise-protective headphones ED1H Ear Defender (Fig. 8, curve 2) with the developed CIPD (Fig. 8, curve 3) performed under correlated conditions demonstrates that, in terms of noise-protective properties, it corresponds completely to the requirements for modern HPD.

Fig. 9 represents dependence graphs $T=f(\tau)$ for CIPD test sample.

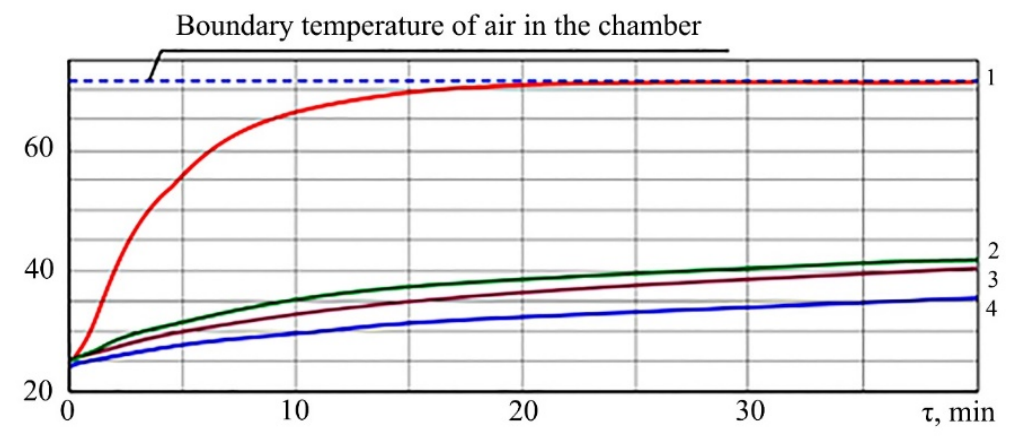

Fig. 9. Dynamics of temperature changes on a dummy-head: 1 - external surface; $2-4$ - under CIPD in terms of frontal, parietal, and occipital parts respectively.

Experiments have demonstrated the following. After placing a dummy-head with balaclava (with thermal protecting elements) into the heated thermal chamber (Fig. 9, curve 3), average heating rate (AHR) of the external dummy surface (within the considered section) is $\sim 9-11^{\circ} \mathrm{C} /$ min (Fig. 9, curve 1) while sensors set under CIPD within frontal, parietal, and occipital parts record slower temperature growth: AHR is not more than $1.5-2{ }^{\circ} \mathrm{C} / \mathrm{min}$ (Fig. 9, curves $2 \div 4$ ) that is almost $80 \%$ less comparing to the values obtained without CIPD use.

Results of approbation performed in the context of three mining, metallurgical, and coal-graphite branches have proved that CIPD tested under industrial conditions is 
characterized by good ergonomic, protective, and operational properties; besides, the device protects facial skin and head hair-covering against dust and dirt, favours better headprotective helmet contact being combined well with protective goggles of various design.

Following factors have been also emphasized: handiness, possibility to communicate while wearing the device, sufficient level of external industrial-noise reduction in terms of preserved possibility to hear warning signals, and easy washing and replacing of aerosol, noise-protective, and thermal-accumulating elements.

CIPD may be recommended to be used by engineering and technical staff of multi-field industrial enterprises as well as by the civilians in case of emergency situations and during disaster clean-up operations.

\section{Conclusions}

The studies have demonstrated that CIPD is rather efficient providing:

- average values of suction coefficient is $1.5 \%$ being almost by $30 \%$ less than the indices of standard filtering respirators of similar protective class;

- noise attenuation within the range of $4000-8000 \mathrm{~Hz}$ is from 19 to $26.7 \mathrm{~dB}$;

- in terms of verbal frequency range $(0.5 \div 2.0 \mathrm{kHz})$, acoustic efficiency is up to $8 \div 16 \mathrm{~dB}$; that helps preserve the possibility of communication and timely reaction to warning signals;

- use of CIPD with thermal protecting elements makes it possible to reduce temperature of head heating by $80 \%$ comparing to the results obtained in case when protective devices are not used.

The developed special-purpose balaclava with the built-in dust respirator and noiseattenuating elements may be used in terms of corresponding class of filters up to $12 \mathrm{MAC}$ as for the most hazardous aerosols when noise level is up to $14 \mathrm{~dB}$ within the frequency range of $2000-8000 \mathrm{~Hz}$; it provides slow temperature growth up to $2{ }^{\circ} \mathrm{C}$ per minute.

This work was conducted within the projects "Scientific basics to form unified system to preserve and generate power of the objects of fuel and energy complex of Ukraine" (State registration No. 0117U001127).

\section{References}

1. Tkachishyn, V.S., \& Bohomolets, O.O. (2004). Effect of industrial noise upon a human organism. National Medical University, (3), 96-102.

2. Smagulov, N.K., \& Alpysbaieva, Zh.T. (2012). Physiological evaluation of the working conditions effect upon the indices of workers' health in terms of basic professions of cokechemical production. Messenger of TVSU. Series “Biology and Ecology”, 25(3), 36-42.

3. Mishchenko, I.M. (2012). Merrous metallurgy and environmental protection. Donetsk: Donetskyi natsionalnyi tekhnichnyi universytet.

4. Smagulov, N.K., \& Alpysbaieva, Zh.T. (2010). Subjective evaluation of working conditions and workers' health in terms of coke-chemical production. Health and Disease, (1), 41-47.

5. Khomenko, O., Kononenko, M., \& Myronova, I. (2013). Blasting works technology to decrease an emission of harmful matters into the mine atmosphere. Annual Scientific-Technical Collection - Mining of Mineral Deposits 2013, 231-235. https://doi.org/10.1201/b16354-43

6. Helmet liners and balaclava-masks. (2018). Retrieved from http://www.komplekt.ua/catalog/sredstva_zashchity_golovy/

7. Helmet liners for protective helmets "Tekhnologii ohrany zdorov'ya" Ltd. (2018). Retrieved from http://protivogaz.com/pages/podshlemniki_pod_kasku_zaschitnuyu.html

8. Hats and Insulated Balaclavas. Legion Safety. (2018). Retrieved from http://www.legionsafety.com/winter-hard-hat-liners-and-hats.html 
9. Occunomix Flame Resistant Full Face Tube Liner LK910FR \& LK910NFR. Legion Safety. (2018). Retrieved from http://www.legionsafety.com/occunomix-lk910nfr-lk910fr-flameresistant-full-face-tube-liner.html

10. Luinenburg, D.M., Mullins, E.H., Danisch, S.G., \& Nelson, T.J. (2003). Evaluation of a Quantitative Fit Testing Method for N95 Filtering Facepiece Respirators. American Industrial Hygiene Association Journal, 64(4), 480-486.

11. Ennan, A.A., Sakharov, O.V., Abramov, N.M., \& Cheberiachko, S.I. (2016). Complex Individual Protective Device. Patent No 113669, Ukraine.

12. Ennan, A.A., Baidenko, V.I., Abramova, N.N., Basmanov, P.I., \& Shneider, V.G. (2002). Practice of development of implementation of light-weighted filtering gas and dust respirators Snezhhok GP. In The $1^{\text {st }}$ International scientific and practical conference "Environmental protection, health, safety in welding industry", (pp. 255-276). Odesa.

13. Koshcheiev, V.S., \& Kuznets, Ye.I. (1986). Physiology and hygiene of individual protection for people in terms of high temperatures. Moskva: Meditsina.

14. DSTU EN 149:2003. (2004). Individual respiratory devices, Filtering half-masks. Requirements, tests, grading. Kyiv: Derzhspozhyvstandart.

15. Alimov, N.P., \& Kniazev, A.S. (1987). Calculation of audiometric efficiency of noise individual protective devices. Labour safety at production. Collection of scientific papers of the institutes of labour protection of All-Union Central Council of Trade-Unions, 21-25.

16. Cheberiachko, S., Yavorska, O., Cheberiachko, Y., \& Yavorskyi, A. (2018). Analysis of pressure difference changes in respirator filters while dusting. E3S Web of Conferences, (60), 00012. https://doi.org/10.1051/e3sconf/20186000012

17. DS18B20 Programmable Resolution 1-Wire Digital Thermometer. Maxim Integrated. (2018). Retrieved from https://datasheets.maximintegrated.com/en/ds/DS18B20.pdf 